Meta

Journal des traducteurs

Translators' Journal

\title{
Interlanguage and its Manifestations in Translation
}

\section{Gideon Toury}

Volume 24, numéro 2, juin 1979

URI : https://id.erudit.org/iderudit/004502ar

DOI : https://doi.org/10.7202/004502ar

Aller au sommaire du numéro

Éditeur(s)

Les Presses de l'Université de Montréal

ISSN

0026-0452 (imprimé)

1492-1421 (numérique)

Découvrir la revue

Citer cet article

Toury, G. (1979). Interlanguage and its Manifestations in Translation. Meta, 24(2), 223-231. https://doi.org/10.7202/004502ar d'utilisation que vous pouvez consulter en ligne.

https://apropos.erudit.org/fr/usagers/politique-dutilisation/ 


\section{Interlanguage and its Manifestations in Translation*}

\section{A}

During the last few years, especially since Larry Selinker's 1972 article, the concept of sinterlanguage \& has been gaining a prominent status in applied linguistics. What Selinker maintained was that in the process of second-language learning, not only two linguistic systems are involved, the mother tongue (SL) and the target language, i.e., the language one is trying to learn (TL), but \& [...] one would be completely justified in hypothesizing, perhaps even compelled to hypothesize, the existence of a separate linguistic system based on the observable output which results from a learner's attempted production of a TL norm. This linguistic system we will call \& interlanguage » (IL) » (Selinker, $1972: 214$ ). As reflected by the term chosen by Selinker, this system enjoys an intermediate status between SL and TL, and in the main it reflects the interference of these two codes in the performance of the learner while producing utterances in the language which he is in the process of learning.

Other scholars have also dealt with this phenomenon, under various titles, reflecting different points of emphasis, such as Corder's «transitional language \$ $(1973: 149 ; 1975: 410)$ or Nemser's « approximative system » (1971). Naturally, most of the work was continually done in the framework of foreign-language learning and teaching : not only are the manifestations of this linguistic variant very frequent in the utterances of foreign-language learners, but, in addition, many of the applied linguists tend to concentrate their own efforts on problems having direct bearing on language teaching (if not to reduce the entire discipline to this branch). Little wonder, then, that very often their attitude towards interlanguage is * appliedly \& biased (if I may use such a barbarism) : while being conceived of as an indispensable phase in the process of foreign-language learning, it tends to be regarded mainly as a phase, i.e., a temporary, changeable state of affairs, the main justification for whose study is to find proper ways of cutting its measure down, if not altogether eliminating it. After all, as Pit Corder so nicely put it, the applied linguist wants to be useful $\gg(1973: 265)$. As a result, the work on interlanguage is looked upon mainly as part of "error analysis »,

* Paper read at the 5th International Congress of Applied Linguistics, August 1978, Montréal. An abstract appeared in Language and Language Behavior Abstracts (No. 78S00387/AILA/1978/0370). 
that is, this linguistic variant is from the beginning regarded as an undesirable state of affairs.

But, desirable or undesirable, this is first of all a linguistic phenomenon ; and there is also theoretical and descriptive interest in interlanguage, non-applied, as it were, both for general and descriptive linguistics and for adjacent disciplines like psycholinguistics and sociolinguistics. Moreover, I can see no point in confining the theoretically and descriptively oriented discussion of this phenomenon to foreign-language learning only. Obviously enough, the distribution of interlanguage forms is of much greater universality : they are likely to occur whenever and wherever one language is used in some contact with another - as one of the most possible consequences of this contact. This hypothesis has already been put forward and convincingly demonstrated by the late Uriel Weinreich in his by now classical study, Languages in Contact (1953), and by many others, and need not be gone into any further now ${ }^{1}$.

\section{B}

One of the purest and most common situations of this type is translation, which inevitably puts the translator, a potential bilingual, in the position of actual, materialized bilingualism, while bringing the two languages themselves, SL and $\mathrm{TL}$, into contact through him and his activity. Thus, it is more than just reasonable to expect the product of his activity, the translated text, to serve as an unfailing source of interlingual phenomena. In this connection, one may again recall Selinker's definition of the linguistic performance of the second-language learner as an «attempted meaningful performance », i.e., a «situation when an «adult» [over the age of 12 , i.e., a competent speaker of his own native language] attempts to express meanings, which he may already have, in a language which he is in the process of learning $\gg$ (Selinker, $1972: 210$ ). Obviously, this formulation is a near-paraphrase of a common definition of translation, though translation carried out in unfavourable conditions : from SL in which the speaker is competent into TL where his competence is only partial and insufficient.

But translation in favourable conditions, between two languages that the translator is a competent speaker of, or even translation into his own mother tongue, also abounds in manifestations of interlanguage. Thus, although lack of mastery of TL is doubtless a supporting factor for the occurrence of such forms, and may not only contribute to their frequency but also affect their form and nature, it can by no means be regarded as either a principal or necessary condition for the production of interlanguage. Actually, the claim should be even stronger. I would claim that the occurrence of interlanguage forms in translation follows from the very definition of this type of activity/product, thus being a formal «translation universal ». (For the difference between the substantive and formal types of universals, cf. Chomsky, 1965 : 28-29.) Moreover, there are situations where interlanguage as a whole, or at least certain types/degrees of it, is not

1. But cf. now Even-Zohar's « Universals of Literary Contacts », in Even-Zohar, 1978a : 45-53. 
simply present in translations as living evidence of the universal, but even preferred to «pure » TL forms. Thus, again, one should not regard these forms as mere misperformance and indulge in "error analysis », but concern oneself first and foremost with the phenomenon qua phenomenon, which may on occasion be a clear indication of the concepts of translation and translation equivalence underlying the corpus under study and governed by the position of translation as a sociocultural linguistic activity and of its products, the translated texts, in the target social, cultural and linguistic systems (for these matters cf. Even-Zohar, 1978 ; Toury, $1977 ; 1978 \mathrm{a} ; 1978 \mathrm{~b}$ ). Thus, the analysis of interlanguage forms occurring in translations should form an integral part of any systematic descriptive study of translation as an empirical phenomenon.

\section{C}

Obviously, this claim implies the need for a theory of translation, which differs essentially from most of the existing ones. As is well known, these theories proceed from ST (or even SL) and set conditions for translation equivalence, and hence for regarding texts as translations, according to some a priori criteria, in terms of a certain required relationship (or class of relationships) between TT and ST, or even between the entire corresponding linguistic systems, TL and SL, plus a certain required «well-formedness $»$ with regard to the target system. As a result, they are willing to accept as translations only « correct», «maximal » (or at least «optimal») instances of performance from the point of view of the norms they set. In other words, they are more of translatability theories (under certain conditions) than theories of actual translation, let alone of actual translations.

Analogously to what I previously said about linguists and their attitude towards interlanguage, it may be argued that such theories of translation are « applied » in orientation, and hence « applied » in one's capacity to use them as well. While able, e.g., to serve as a basis for the training of translators willing to accept their norms, they are totally unable to supply a sound starting point and framework for a descriptive study of actual translations, most of which adhere to norms which are different from the ones postulated by the existing theories of translation.

On several occasions, most recently in a paper entitled « Translated Literature - System and Norm », read at the international symposium on « Translation Theory and Intercultural Relations » held at Tel Aviv University on March 27 April 1, 1978 (Toury, 1978b), I have claimed that the most suitable starting point for a descriptive study of translations and translational relationships as empirical phenomena in their environment is TT-oriented - and non-normative in nature. As opposed to the «traditional » ST/SL-oriented theories of potential translatability, the initial question of such a theory is not whether a certain text is a translation, according to some pre-conceived criteria which may well be extrinsic to the systems in which the text in question is, or is to be, integrated, but whether it is regarded as a translation from the intrinsic point of view of the target system. This is the only type of theory which may supply a theoretically founded mechanism for a systematic and exhaustive description and explanation of every 
phenomenon occurring, or capable of occurring, in translation, including all the existing and possible TT-ST relationships.

In terms of such a mechanism, which I tentatively put forward a few years ago (Toury, $1976 ; 1977: 48-84$ ), interlanguage corresponds to the \& material 》, formal type of TT-ST (TL-SL) relationships ( \& formal equivalence »), which stands in binary opposition to the functional type of relationship by virtue of the former focusing on substance-units and the latter - on functional units (i.e., substance + functions). In a schematic representation : SL linguistic means $\rightarrow$ TL/SL linguistic means, that is, a direct substitution of linguistic means for linguistic means - either existing or created ad hoc - without taking into account their functions in the two linguistic systems, SL and/or TL, as well as in the two texts involved, ST and/or TT.

Formal equivalents in TL of ST/SL units or structures may be formed in three ways, with no clear-cut borderlines betwween them :

1) Altogether outside the TL code, in full (e.g., direct copying from ST/SL) or in part (e.g., transcribing or transliterating ST/SL units while adapting them to the phonological, graphological, or even morphological and grammatical systems of TL) ;

2) Between the two codes (e.g., loan-translation, or the creation of new TL forms and structures from existing ones formally corresponding to SL forms and structures, by further approximation to the latter) ;

3) Seemingly within the TL code, but under obvious influence of SL/ST (e.g., showing preference for certain TL forms or structures - because of their normal correspondence to some SL forms or structures - to other TL linguistic means which do not exhibit such a correspondence, with no regard for questions of functional equivalence).

In connection with the last mode of formal equivalence it should be noted that formal correspondence (and interlanguage) do not necessarily only manifest themselves in odd forms with regard to TL of the \& non-existing \$ type (i.e., in deviations from the code proper), but also in odd forms of the « unusual » type, which are deviations from the norm of usage. Thus, a certain frequency of forms or structures having formal correspondences in another language, which is greater than usual in TL, may tentatively mark the text in question as being a translation.

$\mathbf{D}$

The analysis of thousands of pages translated into Hebrew and English allows me to claim that virtually no translation is completely devoid of formal equivalents, i.e., of manifestations of interlanguage. This fact, again, is in striking analogy to what we know about second-language learning. As Selinker put it, 4 absolute success in a second language affects, as we know from observation, a small percentage of learners - perhaps a mere 5\%》(Selinker, 1972 : 212). This is why it is relatively easy to identify translation as such, along with its SL, 
or to identify a mediated, second-hand translation as being second-hand, including the mediating language (or even the very translated text which served as immediate ST for it). The deliberate utilization of interlanguage forms is also one of the main means that a writer who wants to pass an original text for a translation has at his disposal (the case of the so-called «pseudotranslation », or « fictitious translation 》 (c.f., e.g., Popovic [1976] : 20).

But this is not a mere empirical, observational conclusion. Theoretical considerations highly verify it, and even lead to hypothesizing that the language used in translation tends to be interlanguage (sometimes designated «translationese 》), or that a translation is, as it were, an «inter-text », by definition. Let us look at some of these considerations.

It is well known that translation involves and reflects a tension between two incompatible postulates : an adequacy postulate, dictating maximal representation of a pre-existing text composed in another language, and an acceptability postulate, dictating the appropriate position of TT within the relevant target system(s). This opposition is sometimes semi-popularly formulated as being between « reading as the original » and « reading as an original ». Thus, every actual translation occupies a certain position between these two postulated extremes. This position cannot be defined in advance because it is ever-changing, and its establishment forms an integral part of the study of translation performance. One thing is sure, though : it never coincides with any of the two polar alternatives. It is the inherent difference between adequacy and acceptability which explains the inevitable occurrence of interlanguage in translation : it is the outcome of the actual "combination of (or compromise between) these two extremes (Toury, 1978a : 89).

Since the concept of translation includes not only adequacy and acceptability postulates, but also an equivalence postulate, it is obvious that the variation and changeability of the concept of translation between adequacy and acceptability involve a corresponding variation of translation equivalence. In other words, the study of actual manifestations of translation equivalence (or : of translation equivalence as an empirical phenomenon) is tantamount to the study of its intermediate position between absolute adequacy (which is possible only in a SL utterance, ST) and absolute acceptability (which is possible only in a TL utterance).

Thus, there is a great difference between linguistic and translation equivalence : inter- or intra-linguistic equivalence is a bilateral relationship : $a$ is the equivalent of $b$ (in respect $c$ ) inasmuch as $b$ is the equivalent of $a$ (in the same respect c). As against it, translation equivalence is a unilateral, irreversible relationship of TT/TL to ST/SL. Thus, linguistic equivalents are interchangeable in a certain situation in principle, whereas a translation equivalent replaces a unit or a structure of another text/language in practice. In other words, linguistic equivalents maintain corresponding positions in the "economy linguistic system, whereas translation equivalents maintain corresponding positions in the \& economy » of a text, a linguistic performance, whether they have such a position in the entire linguistic systems or not. 
The intermediate status does not annul the possibility of regarding \& translationese 》 (or any other variant of interlanguage) as a linguistic system (or code) in its own right : it has the structural properties of a language, it is used for communication purposes, and successfully used, and its user, the translator, is a «native speaker of that language. Obviously, on the most immediate level it is only an idiolect, an idiosyncratic variant that one translator (or even one translator during the translation of one text) is the only native speaker of. But translation, like any other behavioural (or social) activity, is to a large extent governed by inter-subjective norms. Therefore, a big and substantial enough shared nucleus can be found for groups of translations and translators, which allows us to regard it as a dialect, if not as a full-fledged language.

It follows that the descriptive study of any «translationese 》 involves elements of descriptive and contrastive linguistics (in order to identify deviations both from SL and from TL, or, in terms of a theory of translation, both from adequacy and from acceptability, including the modes and degrees of interference), of psycholinguistics (in order to account for the mental mechanisms and processes involved in linguistic contacts) and sociolinguistics (in order to account for their social, sociocultural and sociolingual aspects). Thus, translation studies (an overall name for our discipline, first suggested by James S. Holmes : 1972) should no doubt be an inter-disciplinary discipline.

\section{E}

Let us now consider a small example, which may serve to illustrate several of the points made in this paper : a Hebrew native speaker encountering the following Hebrew sentence : "'oto ? be-ze ha-rega. 'et ha-me'ilon, bi-ršutxa. ve-'ardalonim 'ayin? » [Literally : «Him? At this very moment. The small-coat, if you please. Why, no small-galoshes ?»] (Bulgakov. 1974 : 9).

To be sure, Hebrew does have a number of diminutive suffixes, including -on, which is used twice in this sentence; but : (a) they are semi-productive only; (b) they are used as proper diminutives, i.e., they denote actual, physical diminution of the object denoted by the noun preceding them. Thus, the immediate impression is that this sentence deviates from the Hebrew norm rather than from the Hebrew code, because the suffix -on is attached here to two nouns which do not usually take it : me'il (coat) and 'ardal (the singular form of 'ardalayim, galoshes). Had it referred to a gnome, or to a little child, the deviation from the linguistic code would have been minimal.

But since the wider context informs the reader that the addressee of the sentence is an ordinary grown-up, so that his coat and galoshes are not supposed to be smaller than normal ones, the sentence strikes him as more deviant than the first impression he had, because he must realize that the diminutive suffix has not been used in its normal Hebrew function. Nevertheless, it does not strike him as an error, nor even as the utterance of a speaker in a language "which he is in the process of learning 》 (Selinker, 1972 : 212). Every competent reader of Hebrew at once suspects not only that this sentence is translated, but also that 
its SL was Russian, because the Russian-Hebrew «translationese 》 is a well established linguistic fact in the Hebrew framework. That is why he does not have to know any Russian in order to identify the boasting air of the addresser of this sentence, to which a grain of flattery is added, which is based on other functions that the formal correspondents of the Hebrew diminutive suffix -on have in the « model » language (to use Weinreich's terminology).

Thus, from the point of view of Hebrew translational norms, this sentence and its like are no deviations at all. They are intentional solutions to translation problems, i.e., translation equivalents devised along lines established in a long tradition of translation from Russian into Hebrew, and for a long time even regarded as the only proper solutions for these problems, even though in the beginning they highly deviated from the norms of «pure» Hebrew (and cf. section F).

\section{F}

Up till now we have focused on the results of a direct interference between TL and the actual SL, which might be viewed as "first-order interlanguage ». But \& second-order interlanguage $»$ is possible too, i.e., formal equivalence of TL to a language other than the actual source language of the text. This possibility is reflected in both intermediate and direct translation :

1) In intermediate (second-hand) translation it means the interference of the actual mediating language (which functions as a second-order SL), which is in itself a first-order interlanguage between the actual SL and the mediating, first target language, created while carrying out the mediating translation ;

2) In direct translation it has two possible manifestations : 1. the interference of a third language known to the translator himself (who is then, as it were, in a multilingual situation), either with TL only - locally, or in a more general way (that is, as a fixed, permanent inter-idiolect), or via a second interference, with SL; 2 . the interference of some third language, NL, enjoying a highly privileged status among the speaking community of TL (even though the translator personally may not know this language!), especially when translating from SL which is very little privileged. Here, again, there may occur either a direct interference, of NL itself, or the interference of an interlanguage NL-TL, which has already become institutionalized to a certain extent.

Translation into Hebrew during the thirties and forties supplies a case in point for the abundant employment of «translationese » of all possible types and degrees (cf. Toury, 1977 : 135-236). Apparently, the initial norm prevalent in this period dictates withdrawal from the adequacy pole in favour of rendering the translated texts maximally acceptable in the Hebrew linguistic system. Thus, the basic model to which the translators subject themselves is highly puristic. The more so, because it is based on parts of the written system only : it requires reliance on actually documented language, and on language documented in certain texts and types of texts only. In spite of this very strict norm, many exceptions to the pure Hebraistic model are found, most of them clear cases of formal equivalence. 
Among these there are, of course, many forms reflecting simple first-order interlanguage, between the actual SL as used in ST and Hebrew. These cases, although an exception to the puristic model, are at least understandable on the grounds of the mechanism of direct contact between two languages in a bilingual situation. For that reason, much more striking than these cases are the many instances of formal equivalence of the second order : the interlanguage Russian-Hebrew, or Russian-Hebrew-SL, appearing while translating non-Russian texts. These cases prove that because of its culturally highly privileged status, the interference of the Russian language in the Hebrew system as a whole was so powerful that it could neutralize both the pretensions that the latter had to purism and the mechanism of direct contact between TL and SL.

However, the most interesting thing is that although these two types are obvious cases of interlanguage, i.e., non-puristic mixtures, attempts have constantly been made to give them a secondary justification within the normative linguistic model. Naturally enough, this has been done mainly in one way : by showing the existence of formally parallel forms in old Hebrew writings - rare, unique and functionally different as they may be - which obviously fulfill the most puristic requirements while being, in fact, a narrow excuse only ${ }^{2}$.

Dr. Gideon Toury

\section{REFERENCES}

BULGAKOV, M., 1974, «Ha-šeleg ha-šahor» : Roman te'atroni, tr. Zvi Arad. Tel Aviv : Am Oved.

CHOMSKY, Noam, 1965, Aspects of the Theory of Syntax, Cambridge (Mass), The M.I.T. Press.

CORDER, S. Pit, 1973, Introducing Applied Linguistics, Penguin Books.

— 1975, «The Language of Second-Language Learners », The Modern Language Journal, 59, No. 8 (December) : 409-413.

EVEN-ZOHAR, Itamar, 1978, «The Position of Translated Literature within the Literary Polysystems $\gg$, in : Holmes et al., $1978:$ 117-127. Also in : Even-Zohar, 1978a : 21-27.

- 1978a, Papers in Historical Poetics, Tel Aviv, The Porter Institute for Poetics and Semiotics, Tel Aviv University. [Papers on Poetics and Semiotics, 8.]

HOLMES, James S., 1972, The Name and Nature of Translation Studies, Translation Studies Section, Department of General Literary Studies, University of Amsterdam.

HOLMES, James S., José LAMBERT and Raymond VAN DEN BROECK, eds., 1978, Literature and Translation: New Perspectives in Literary Studies, Leuven, ACCO.

NEMSER, William, 1971, «Approximative Systems of Foreign Language Learners 》, IRAL, $9: 115-123$.

2. «Prescriptive intervention, characteristically, is an area in which linguistic data may converge with the naive notions and biases of the common man; as a result, prescriptive pronouncements can sometimes be quite comical and fallacious in content. Practitioners of prescriptive intervention are very often not professional linguists and, as propagandizers of a particular position, frequently act on emotion rather than on an objective examination of facts» (Wexler, $1974: 7$ ). "The characterizations of the linguist may often differ from those of the native speakers. [...] Moreover, etymologically foreign words or loan translations in a language may be taken for native material and thus avoid possible opposition from regulators 》(Wexler, 1974:20, n. 6). 
POPOVIČ, Anton, [1976], Dictionary for the Analysis of Literary Translation, Edmonton, Department of Comparative Literature, The University of Alberta, Nitra, Department of Literary Communication, the Pedagogical Faculty.

SELINKER, Larry, 1972, «Interlanguage », IRAL, $10:$ 209-231.

TOURY, Gideon, 1976, \&Equivalenzya šel yehidot ve-equivalenzya šel teqstim : Li-š'elat te'ur ha-yehasim ben tirgum u-maqor $\gg$ [Equivalence of Units and Equivalence of Texts : Towards a Description of the Relationships Between Translation and Source]. Ha-sifrut/Literature, 23 (October) : 42-49.

1977, Normot šel tirgum ve-ha-tirgum ha-sifruti le-'ivrit ba-šanim 1930-1945 [Translational Norms and Literary Translation into Hebrew, 1930-1945]. Tel Aviv, The Porter Institute for Poetics and Semiotics, Tel Aviv University [Literature, Meaning, Culture, 6].

1978a, « The Nature and Role of Norms in Literary Translation », in : Holmes et al., $1978: 83-100$.

1978b, «Translated Literature - System and Norm : Towards a TT-Oriented Approach to Literary Translation », Paper presented to the International Symposium on Translation Theory and Intercultural Relations, Tel Aviv University, March 27 April 1, 1978 [to be published in the Proceedings].

WEINREICH, Uriel, 1953, Languages in Contact : Findings and Problems, The Hague Paris, Mouton.

WEXLER, Paul N., 1974, Purism and Language : A Study in Modern Ukrainian and Belorussian Nationalism (1840-1967), Bloomington, Indiana University [Language Science Monographs, 11]. 